\title{
BMJ Open Inferred duration of infectious period of SARS-CoV-2: rapid scoping review and analysis of available evidence for asymptomatic and symptomatic COVID-19 cases
}

\author{
Andrew William Byrne (D) , ${ }^{1}$ David McEvoy (D) , ${ }^{2}$ Aine B Collins, ${ }^{3,4}$ Kevin Hunt, ${ }^{5}$ \\ Miriam Casey (D) , ${ }^{3}$ Ann Barber, ${ }^{3}$ Francis Butler, ${ }^{5}$ John Griffin (D) , \\ Elizabeth A Lane, ${ }^{3,4}$ Conor McAloon (1) , ${ }^{6}$ Kirsty O'Brien, ${ }^{7}$ Patrick Wall, ${ }^{8}$ \\ Kieran A Walsh, ${ }^{7}$ Simon $\mathrm{J} \mathrm{More}^{3}$
}

To cite: Byrne AW, McEvoy D, Collins $A B$, et al. Inferred duration of infectious period of SARS-CoV-2: rapid scoping review and analysis of available evidence for asymptomatic and symptomatic COVID-19 cases. BMJ Open 2020;10:e039856. doi:10.1136/ bmjopen-2020-039856

- Prepublication history and additional material for this paper are available online. To view these files, please visit the journal online (http://dx.doi org/10.1136/bmjopen-2020039856).

Received 30 April 2020 Revised 06 July 2020 Accepted 10 July 2020

D Check for updates

(c) Author(s) (or their employer(s)) 2020. Re-use permitted under CC BY-NC. No commercial re-use. See rights and permissions. Published by BMJ.

For numbered affiliations see end of article.

\section{Correspondence to} Dr Andrew William Byrne; ecologicalepidemiology@gmail. com

\section{ABSTRACT}

Objectives Our objective was to review the literature on the inferred duration of the infectious period of COVID-19, caused by severe acute respiratory syndrome coronavirus 2 (SARS-CoV-2) virus, and provide an overview of the variation depending on the methodological approach. Design Rapid scoping review. Literature review with fixed search terms, up to 1 April 2020. Central tendency and variation of the parameter estimates for infectious period in (A) asymptomatic and (B) symptomatic cases from (1) virological studies (repeated testing), (2) tracing studies and (3) modelling studies were gathered. Narrative review of viral dynamics.

Information sources Search strategies developed and the following searched: PubMed, Google Scholar, MedRxiv and BioRxiv. Additionally, the Health Information Quality Authority (Ireland) viral load synthesis was used, which screened literature from PubMed, Embase, ScienceDirect, NHS evidence, Cochrane, medRxiv and bioRxiv, and HRB open databases.

Results There was substantial variation in the estimates, and how infectious period was inferred. One study provided approximate median infectious period for asymptomatic cases of 6.5-9.5 days. Median presymptomatic infectious period across studies varied over $<1-4$ days. Estimated mean time from symptom onset to two negative RT-PCR tests was 13.4 days (95\% Cl 10.9 to 15.8$)$ but was shorter when studies included children or less severe cases. Estimated mean duration from symptom onset to hospital discharge or death (potential maximal infectious period) was 18.1 days (95\% Cl 15.1 to 21.0$)$; time to discharge was on average 4 days shorter than time to death. Viral dynamic data and model infectious parameters were often shorter than repeated diagnostic data.

Conclusions There are limitations of inferring infectiousness from repeated diagnosis, viral loads and viral replication data alone and also potential patient recall bias relevant to estimating exposure and symptom onset times. Despite this, available data provide a preliminary evidence base to inform models of central tendency for
Strengths and limitations of this study

- A comprehensive overview of the literature pertaining to inferred infectious duration of COVID-19, including indirect measures from virological, contact tracing and modelling studies to 1 April 2020.

- Both narrative review and quantitative analysis presented.

- Small number of comparable parameter estimates for meta-analysis is a limitation.

- Much of the current research material on COVID-19 is from preprint papers and therefore have not gone through formal peer review.

key parameters and variation for exploring parameter space and sensitivity analysis.

\section{INTRODUCTION}

Severe acute respiratory syndrome coronavirus 2 (SARS-CoV-2), a new coronavirus, emerged in China in late 2019. ${ }^{2}$ The virus causes COVID-19, a disease characterised by variable, mainly respiratory, symptoms across cohorts, from asymptomatic cases through to mild (eg, dry cough and fever) and severe cases (eg, pneumonia). ${ }^{3}{ }^{4}$ The severity of symptoms, and their clinical outcome, have been reported to vary by age class and whether patients have underlying comorbidities. The case fatality rate increases with age and is highest for those above 70 years. ${ }^{56}$ There are several cases of asymptomatic test-positive patients reported in the emerging literature $(\mathrm{eg}, 478$ ). Furthermore, asymptomatic (and presymptomatic) cases have been shown to be infectious, and secondary cases have been reported. ${ }^{910}$ However, the duration of this 
infectious period is difficult to measure accurately, and the time course of the natural history of infection generally must be inferred indirectly, via contact tracing of cases, serial repeated diagnostic virological studies and/ or through modelling approaches. Symptomatic cases can experience an infectious presymptomatic period before the onset of symptoms, therefore understanding the whole infectious period for this cohort requires estimating the duration of both periods. It is essential to rapidly gain insight into this key variable impacting our understanding of COVID-19 epidemiology. Anderson et $a l^{11}$ point out one of the 'key unknowns' is the infectious period for COVID-19, which they suggest may be 10 days but subject to great uncertainty.

Here we gathered data from published research from peer-reviewed and preprints from 1 December to 1 April 2020 to characterise the variation in the infectious duration inferred from the three lines of evidence. We also provide a narrative review of the viral dynamic literature. Our focus was on duration; relative infectiousness has been dealt with elsewhere. ${ }^{12} 13$

The aim of this review was to provide an overview and critical appraisal of published and preprint articles and reports that assess or quantify the inferred duration of the infectious period in order to best parameterise COVID-19 epidemiological transmission models.

\section{MATERIALS AND METHODS}

\section{Conceptual model of population infection dynamics}

Infectious period was contextualised in relation to a working conceptual model of COVID-19 disease dynamics (online supplementary figure S1, online supplementary material 1). From this conceptual model, three parameters were identified as important in context of this study:

- T2 defined as: duration of the total infectious period for asymptomatic cases, postlatent to recovery ('recover' in this context relates to clearing of infection).

- T3 defined as: duration of presymptomatic infectious period for those infected individuals who subsequently develop symptoms (ie, postlatent to onset of symptoms).

- T5 defined as: duration from onset of symptoms to recovery (recovery was inferred as either the first of two clear RT-PCR tests or hospital discharge after admission from COVID-19-related symptoms) or death.

'Asymptomatic' case definition was interpreted pragmatically following Davies $e t a l^{1415}$ and may include very mild symptoms that may occur but are unnoticed.

$\mathrm{T} 2$, T3 and T5 represent readily measurable parameters but may be upper limits of infectious period, as patients may be non-infectious for a period before recovery or death. We also review evidence where infectiousness is inferred from viral shedding and contract tracing (transmission).

\section{Literature search}

A survey of the literature between 1 December 2019 and 1 April 2020 for all countries was implemented using the following search strategy. Publications on the electronic databases PubMed, Google Scholar, MedRxiv and BioRxiv were searched with the following keywords: 'Novel coronavirus' OR 'SARS-CoV-2' OR '2019-nCoV' OR 'COVID-19' AND 'infectious'. Additionally, national and international government reports were monitored. No restrictions on language or publication status were imposed so long as an English abstract was available. Articles were evaluated for data relating to the aim of this review; all relevant publications were considered for possible inclusion. Bibliographies within these publications were also searched for additional resources.

Manual searches of the literature was undertaken using daily updated COVID-19 collections from the National Centre for Biotechnology Information and MedRxiv servers (https://connect.medrxiv.org/relate/content/ 181), respectively, searching specifically for papers relating to 'infectious period' or 'infectious duration' from both empirical and modelling studies.

Finally, we used the complementary work undertaken by the Health Information and Quality Authority (HIQA) of Ireland, specifically the evidence summaries relating to asymptomatic transmission and viral load. ${ }^{16} 17$ The protocol for the evidence synthesis is published on the HIQA website. ${ }^{18}$ Briefly, the evidence synthesis process included searching databases from 30 December 2019 to 27 March 2020 (PubMed, Embase, ScienceDirect, NHS evidence, Cochrane, medRxiv and bioRxiv, and HRB open), screening, data extraction, critical appraisal and summarising the evidence.

Our aim was to have as great a breadth for an evidential base as possible to clarify what evidence was available to inform on the infectious period of COVID-19 and to identify key characteristics of the data sources and their interpretation. Therefore, our approach is a scoping review (following ${ }^{19}$ ). However, due to the emergent nature of COVID-19, this work is considered a rapid review. ${ }^{20}$ This paper follows the Preferred Reporting Items for Systematic Reviews and Meta-Analyses-Extension for Scoping Reviews (PRISMA-ScR) checklist. In accordance with the PRISMA-ScR checklist, the electronic search strategy can be found in the supplementary material (online supplementary material 2 ).

Inclusion criteria were for papers that provided data to inform duration of infectious period based on: time from symptoms to recovery; time from symptoms to death; time from symptoms to diagnostic test clearance ( $\geq$ two clear tests, defined as at least two consecutive negative reverse transcriptase PCR (RT-PCR) tests conducted 24hours apart); presymptomatic infectious period; and time from first diagnostic test to diagnostic test clearance ( $\geq$ two clear tests) for presymptomatic/asymptomatic cases. Inclusion criteria for viral dynamics were papers that reported viral load via cycle threshold (Ct) values from RT-PCR testing over repeated 
sampling of infected patients and studies that additionally reported viral isolation.

For quality control, studies were: (1) selected and screened initially by three members of the team from search terms outlined above ( $A B C, K H$ and $F B$ ), with parameters identified and recorded. (2) This was reviewed and supplemented by manual search by a different two team members $(A W B$ and $D M$ ), again with parameters identified and recorded. (3) Finally, the review was then internally reviewed by an additional two members of the team $(C M c$ and $M C)$ and cross-referenced with other parameter synthesis documents being worked on by the group (all authors).

\section{Parameter comparison}

\section{Parameters of interest}

- A priori, it was decided to harvest parameter estimates for: (1) asymptomatic and (2) symptomatic cases. As the period of infectiousness can only be estimated indirectly, parameter estimates from the literature was gathered from three different methodological approaches:

- Virological studies tracking patients overtime undertaking serial testing, where infectious period was inferred from diagnostic testing history and/or by virus isolation.

- Contact tracing studies where infectiousness is inferred by infector-infectee histories and/or clusters of infection.

- Model parameters entered into mathematical models (priors) representing explicitly infectious periods or model parameters estimated from mathematical models (posterior estimates) estimating explicitly infectious periods

\section{Visual and quantitative comparisons}

To compare parameters visually, simulated distributions were estimated from the central tendencies and variation metrics described in the primary literature. To simulate data, 10000 random variates were drawn from random number functions in Stata (ME, V.15.1; StataCorp. 2017. Stata Statistical Software: Release V.15) (rnormal and rgamma). Where possible, the distribution reported within the primary literature was used to represent the distribution (eg, Gaussian and gamma). Where distributional data could not be inferred, point estimates were presented.

There were adequate comparable data gathered on the duration of T5 (duration from onset of symptoms to death or recovery) from virological studies to employ a metaanalytic model. Many of the studies report different central tendency estimates, including mean and median. Methods of reporting variation across this central tendency included $\mathrm{SD}$, range, IQR. To facilitate meta-analysis, reported estimates from all studies were converted to the mean and SD based on the formulae given in Wan et al. ${ }^{21}$

To obtain the SD from $95 \% \mathrm{CI}$, the method outlined in the Cochrane handbook ${ }^{22}$ was used:

SD: $\sqrt{ } \mathrm{n}$ (Upper limit of CI - Lower limit of CI)/3.92

SE was calculated from SD and sample size (n), using:
$\mathrm{SE}=\mathrm{SD} / \mathrm{SQRT}(\mathrm{n})$

Comparisons were made using the METAAN package in Stata V.15, using the random-effects (DerSimonianLaird) model. ${ }^{23}$ This model assumes heterogeneity between the studies; that is, it assumes that the true effect can be different for each study. The model assumes that the individual study true effects are distributed with a variance $\tau^{2}$ around an overall true effect, but the model makes no assumptions about the form of the distribution of either the within-study or the between-studies effects. Weightings were derived from the SE (precision) around the estimate. Comparisons were presented as forest plots. Heterogeneity between studies was tested using Cochrane's $Q$; the magnitude of the heterogeneity was categorised using $I^{2}$ as high $(>75 \%)$, moderate $(50 \%-$ $75 \%)$ or low $(<50 \%){ }^{24}$

Variation in duration across $\mathrm{T} 5$ virological studies was compared using a random effects (RE) meta-regression model, using the METAREG command in Stata V.15.1. The hypothesis that heterogeneity may be related to the inclusion of children or depending on symptom severity within the sample was tested in separate univariate models. Severity was dichotomised $(0 / 1)$ into studies that included patients described as having 'mild' or 'mild-moderate' symptoms versus studies that included patients with 'moderate-severe' or 'severe' symptoms. Similarly, studies were categorised into having some samples from 'children' (as reported in the paper), or wholly adult samples. These variables were then fitted as a dichotomous dummy predictor (independent variable). The parameter estimates from the regression model was solved using restricted maximum likelihood; additionally, $\mathrm{p}$ values were estimated using a Monte Carlo model with 1000 permutation test. ${ }^{25}$

Raw patient-level data were available from three studies in relation to time from onset to hospital discharge or death (potentially inferring maximal T5 duration). To estimate the predicted mean and 95\% CI duration across these studies, data were analysed using a Gaussian RE model (using XTREG command, Stata V.15), with study categories fitted as the RE. A linear regression model with 'study' fitted as a categorical dummy variable was used to estimate the difference between duration across study datasets. Code and data are provided in online supplementary material 3 $\& 4$.

\section{Viral dynamics}

A narrative comparison of reported viral dynamics from studies that undertook serial viral load estimates from patients over their period of observation was undertaken. Trends in the literature, strength and weaknesses were identified, and a conceptual model was illustrated.

\section{RESULTS}

Parameter comparison

Overall, 65 parameter estimates were harvested from 48 papers (tables 1-3). 
Table 1 Reported infectious period (IP) for asymptomatic cases (T5 parameter) from virological studies where serial diagnostic tests were undertaken to infer IP; tracking studies where IP is inferred from contact tracing; modelling studies where $\mathrm{IP}$ is reported as a prior (assumed parameter value) or a posterior estimate

\begin{tabular}{|c|c|c|c|c|c|c|}
\hline Study & Countries & $\begin{array}{l}\text { Parameter } \\
\text { (days) }\end{array}$ & $\mathbf{N}$ & $\begin{array}{l}\text { Central } \\
\text { tendency } \\
\text { reported }\end{array}$ & $\begin{array}{l}\text { Variation (days; } \\
\text { inclusion) }\end{array}$ & Comment \\
\hline \multicolumn{7}{|c|}{ Virological studies } \\
\hline Hu et $a l^{7}$ & China & 9.5 days & 24 & Median & $1-21$ range & $\begin{array}{l}\text { Serial testing. Period between 'onset' (where } \\
\text { onset relates to first positive test) and clearance, } \\
\text { adjudged via two negative RT-PCR tests, } \\
\text { deemed by the authors to be the 'communicable } \\
\text { period'. IQR: } 3.5-13 \text {. }\end{array}$ \\
\hline
\end{tabular}

\section{Tracking studies}

\begin{tabular}{|c|c|c|c|c|c|c|}
\hline Ma et $a l^{8}$ & $\begin{array}{l}\text { China, } \\
\text { Germany, } \\
\text { Japan, } \\
\text { Singapore, } \\
\text { South Korea, } \\
\text { Malaysia and } \\
\text { Vietnam }\end{array}$ & 7.25 days ${ }^{*}$ & 49 & Mean & $\begin{array}{l}95 \% \mathrm{Cl} 5.91 \text { to } \\
8.69\end{array}$ & $\begin{array}{l}\text { *Ma et al do not report infectious period for } \\
\text { asymptomatic cases explicitly within their } \\
\text { paper. The authors estimated the infectious } \\
\text { period as the upper estimated latent period } \\
\text { minus the serial interval, using a dataset of } \\
1155 \text { cases from several countries (latent period } \\
\text { was estimated with } 11 \text { infector-infectee pairs; } \\
\text { serial interval was estimated from } 689 \text { infector- } \\
\text { infectee pairs). } \\
\text { Ma et al reported a mean upper limit of latent } \\
\text { period of } 2.52 \text { days; the mean serial interval for } \\
\text { asymptomatic cases (using date of diagnosis for } \\
\text { onset) was estimated to be } 9.77 \text { ( } 94 \% \text { Cl } 8.43 \text { to } \\
\text { 11.21). }\end{array}$ \\
\hline Hu et $a l^{7}$ & China & & 3 & & 4-9 range & $\begin{array}{l}\text { Cluster of infection within a family, where } \\
\text { the primary case was asymptomatic. The } \\
\text { transmissions to secondary cases occurred over } \\
\text { a period } 4-9 \text { days post the presumed point of } \\
\text { exposure for the primary case. }\end{array}$ \\
\hline
\end{tabular}

\section{Modelling studies}

$\begin{array}{lll}\text { Li et } a l^{27} \quad \text { China } & 3.5^{*} \text { (posterior } \\ & \text { from a model } \\ & \text { estimating } \\ & \text { duration for } \\ & \text { undocumented } \\ & \text { cases) }\end{array}$

Median $3.78 \%$

$95 \% \mathrm{Cl} 3.19 \%$ to $\mathrm{Li}$ et al do not explicitly attempt to model

asymptomatic cases, or their infectious duration. Instead the population infected is divided into 'documented' and 'undocumented'. Documented were all cases where patients had symptoms severe enough to be confirmed infected; all other cases were considered undocumented. Therefore, this estimate represents asymptomatic and 'mild' cases. The $95 \% \mathrm{Cl}$ around the median infectious period estimate was 3.19 to 3.78

\begin{tabular}{|c|c|c|c|c|}
\hline Tuite et $a l^{2639}$ & Canada & 6-6.5 (prior) & $\begin{array}{l}\text { (Fixed } \\
\text { parameter } \\
\text { within a } \\
\text { deterministic } \\
\text { model) }\end{array}$ & $\begin{array}{l}\text { Mathematical model (deterministic), with a fixed } \\
\text { parameter estimate of } 6 \text { or } 6.5 \text { days. Important } \\
\text { to note that duration for 'mild' was equal to } \\
\text { severe cases. }\end{array}$ \\
\hline Davies et al ${ }^{14}$ & UK & 7 days (prior) & Mean & $\begin{array}{l}\text { Model with asymptomatic infection } \\
\text { compartment. Modelled with a gamma } \\
\text { distribution, beta 1.4; alpha } 5 \text {. Despite the } \\
\text { subclinical aspect of this parameter, it could be } \\
\text { considered analogous to total infectious period } \\
\text { without intervention. }\end{array}$ \\
\hline
\end{tabular}

Continued 
Table 1 Continued

\begin{tabular}{|c|c|c|c|c|c|c|}
\hline Study & Countries & $\begin{array}{l}\text { Parameter } \\
\text { (days) }\end{array}$ & $\mathbf{N}$ & $\begin{array}{l}\text { Central } \\
\text { tendency } \\
\text { reported }\end{array}$ & $\begin{array}{l}\text { Variation (days; } \\
\text { inclusion) }\end{array}$ & Comment \\
\hline Davies et $a l^{15}$ & UK & 5 days (prior) & & Mean & & $\begin{array}{l}\text { Model with asymptomatic infection } \\
\text { compartment. Modelled with a gamma } \\
\text { distribution, } k=4 \text {. Authors: 'Assumed to be the } \\
\text { same duration as total infectious period for } \\
\text { clinical cases, including preclinical transmission'. }\end{array}$ \\
\hline
\end{tabular}

RT-PCR, reverse transcriptase PCR.

Infectious period for asymptomatic cases (T2)

The overall distributions and point estimates from studies for $\mathrm{T} 2$ are presented in figure 1 and table 1 .

Two virological studies reported on infectious period based on serial diagnostic testing, for asymptomatic cases, were found to have informative data. One of these studies reported on only one asymptomatic case, with exposure to negative tests being 11 days (table 1). This duration should be considered an overestimate, given that a latent period is not taken into consideration. $\mathrm{Hu}$ et $a l^{7}$ tracked infections of close contacts to infected persons and considered patients asymptomatic at time of diagnosis. Infectious period was defined as time from diagnosis to the first of two clear tests, providing a median duration of 9.5 days $(n=24)$, range: $1-21$; IQR 3.5-13.0.

Importantly, $\mathrm{Hu}$ et $a l^{7}$ found that the infectious period was different between those who subsequently exhibited some symptoms (ie, presymptomatic) and those who did not: the median duration for asymptomatic infectious was 6.0 days (IQR 2.0-12.0; $\mathrm{n}=19$ ). This was reduced to 4.0 days (2.0-15.0) for cases that were asymptomatic without abnormal CT scans $(\mathrm{n}=7)$.

Two tracing studies provide informative data $\left(\right.$ table $1^{78}$ ). Infectious period was inferred indirectly from data provided in Ma et $a l^{8}$, whereby infectious period was estimated as the difference between the upper (maximal) latent period estimate minus the serial interval. Ma et $a l^{8}$ report on 49 asymptomatic cases and inferred serial interval from infector-infectee pairs. Serial interval was calculated by assuming 'onset' was at first diagnosis. Hu $e t a l^{7}$ reported on a case study cluster of infection within a house where the primary case was asymptomatic. Secondary infections occurred 4-9 days after index case exposure, the index patient tested positive until day 29 postexposure.

Modelling studies that have attempted to fit differing parameters depending on the severity of symptoms, and have used differing nomenclature, for example, asymptomatic, 'mild' or subclinical cases (table 1). ${ }^{14} 152627$ Two papers by Davies and colleagues ${ }^{1415}$ model this parameter as a gamma distribution with a mean periods of 5-7 days (figure 2); importantly, these papers assume infectious period is the same for asymptomatic and symptomatic cases.
Presymptomatic: infectious period (T3)

Pan $e t a l^{3}$ and Hoehl $e t a l^{28}$ describe the cases of two individuals tracked and serially tested by real-time RT-PCR after being exposed to a patient with confirmed infection. In the latter study, the virus was isolated from samples, indicating transmission potential.

Four studies from China, Germany and Singapore provide informative data through tracing infections from cluster of infections and through infector-infectee pairs (table 2). ${ }^{492930}$ These papers included the study by Rothe et $a l,{ }^{9}$ which clarified that an asymptomatic patient visiting Germany from China may have actually experienced very mild symptoms around the time that transmission occurred (see Discussion).

Five modelling papers incorporated presymptomatic infectious period reported as prior distributions or estimated as a model output. Two papers describe the prior distribution using a gamma distribution. ${ }^{14}{ }^{15}$ Tindale $e t$ $a l^{31}$ provide mean point estimates under four different scenarios (two populations, early and late epidemic period). Peak $e t a l^{32}$ derives estimates of the presymptomatic infectious duration from a model of serial interval and report scenarios where there are pre-symptomatic infectious periods.

The approximated distributions are simulated in figure 2, which demonstrates the between-study heterogeneity in this parameter. The point estimates primarily cluster around the central tendencies of the distributions, except for Tindale $e t a l,{ }^{31}$ for a model reporting for late occurring cases in Tianjin, China (8.2 days).

\section{Postsymptom onset: infectious period (T5)}

The T5 parameter was informed from three lines of evidence from empirically driven studies:

- Time from symptoms onset to the first of two clear RT-PCR tests.

- Time from symptoms to hospital discharge.

- Time from symptoms to death.

Figure 3 presents the forest plot for the mean time from symptom onset to clearance based on serial testing meta-analysis $(\mathrm{n}=15)$. The mean estimated duration was 13.4 days (95\% CI 10.9 to 15.8). There was high heterogeneity across studies (Cochrane's Q; $\mathrm{p}<0.001 ; I^{2}>75 \%$ ). An $\mathrm{RE}$ meta-regression model suggested significant variation depending on whether studies included children as part 
Table 2 Reported infectious period (IP) for presymptomatic cases (T3 parameter) from virological studies where serial diagnostic tests were undertaken to infer IP; tracking studies where IP is inferred from contact tracing; modelling studies where IP is reported as a prior (assumed parameter value) or an posterior estimate

\begin{tabular}{|c|c|c|c|c|c|}
\hline Study & Location & $\begin{array}{l}\text { Parameter } \\
\text { (days) }\end{array}$ & $\begin{array}{l}\text { Central } \\
\text { tendency } \\
\text { reported }\end{array}$ & $\begin{array}{l}\text { Variation (days; } \\
\text { inclusion) }\end{array}$ & Comment \\
\hline \multicolumn{6}{|c|}{ Virological studies } \\
\hline Hoehl et $a^{28}$ & $\begin{array}{l}\text { Flight from } \\
\text { Wuhan to } \\
\text { Germany }\end{array}$ & 1 & Median & & $\begin{array}{l}\text { Case study of serially tested at risk cohort flying from } \\
\text { Wuhan to Germany. Two patients were asymptomatic } \\
\text { test positive; additionally virus isolation was achieved, } \\
\text { indicating potential infectiousness. }\end{array}$ \\
\hline
\end{tabular}

\section{Tracking studies}

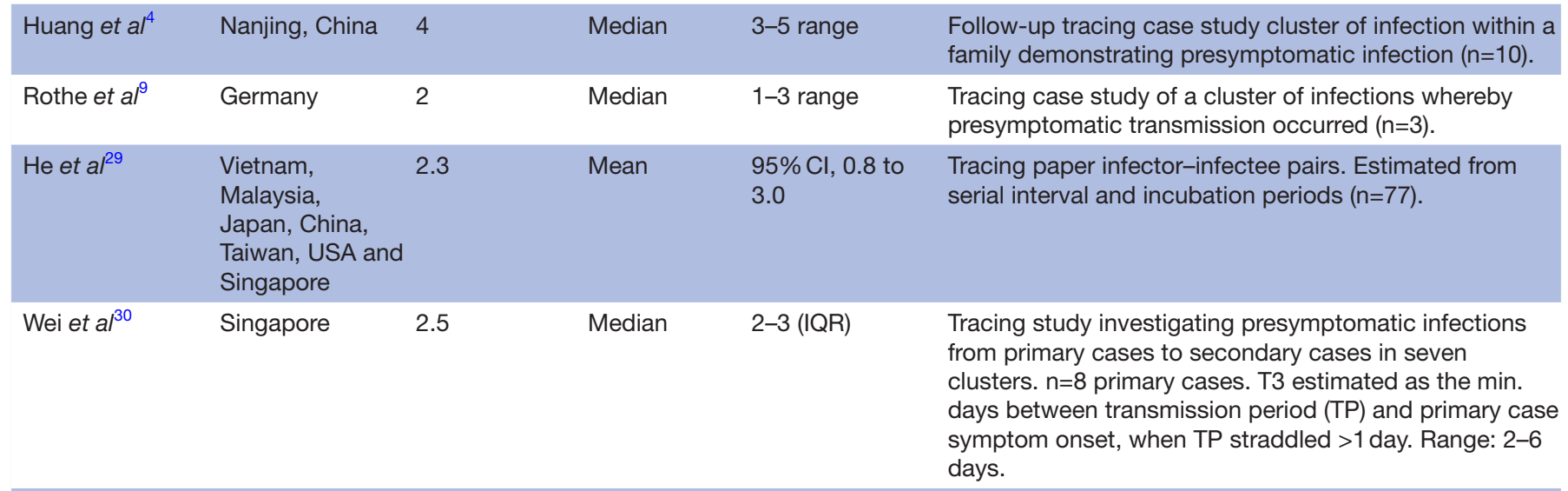

\section{Modelling studies}

$\begin{array}{llll}\text { Peak et }\left.a\right|^{32} \quad \text { Massachusetts } 0.8 \text { (estimate) } & \text { Mean } & -0.29-1.98 \\ 95 \% \mathrm{Cl}^{*}\end{array}$

Modelling paper estimated under two scenarios - a serial interval of 4.8 days or 7.5 days. Under scenario one, the model estimated a period of presymptomatic transmission (median: 0.71). *The lower range was fixed at zero as the model allowed for no presymptomatic infectious case.

\begin{tabular}{|c|c|c|c|c|c|}
\hline Zhu ${ }^{37}$ & Wuhan, China & 1.0 (estimate) & Mean & & $\begin{array}{l}\text { Modelling paper. Model estimated point value - this is a } \\
\text { model derived value. }\end{array}$ \\
\hline Davies et $a l^{14}$ & UK & 2.4 (prior) & Mean & & Modelling paper. Gamma distribution; k=5. \\
\hline Davies et $a l^{15}$ & UK & 1.5 (prior) & Mean & & Modelling paper. Gamma distribution: k=4. \\
\hline Tuite et $\left.a\right|^{2639}$ & Canada & 0.5 to 1 (prior) & Fixed & & $\begin{array}{l}\text { Modelling paper. Fixed parameter within a deterministic } \\
\text { model. }\end{array}$ \\
\hline Ferguson et $\mathrm{al}^{75}$ & UK & 0.5 (prior) & Fixed & & $\begin{array}{l}\text { Modelling paper. Fixed parameter within this model, } \\
\text { whereby infectiousness was assumed to begin } 12 \text { hours } \\
\text { before symptom onset. }\end{array}$ \\
\hline Tindale et $a l^{31}$ & $\begin{array}{l}\text { Tianjin, China } \\
\text { and Singapore }\end{array}$ & $\begin{array}{l}2.9-2.6 \\
\text { (estimate) }\end{array}$ & Mean & $\begin{array}{l}1.2-8.2 \\
\text { mean range, } \\
\text { depending } \\
\text { on early or } \\
\text { late cases, } \\
\text { or whether } \\
\text { in Tianjin, } \\
\text { Singapore }\end{array}$ & $\begin{array}{l}\text { Statistical modelling study estimating period of } \\
\text { presymptomatic transmission inferred from estimates of } \\
\text { serial interval and incubation periods for populations in } \\
\text { Tianjin and Singapore }(n=228) \text {. }\end{array}$ \\
\hline
\end{tabular}

of the sample ( $\mathrm{n}=15$ studies; proportion of between-study variance explained adj. $\mathrm{R}^{2}=43.8 \%$ ). Overall, the model estimated studies including children had on average 5.8 days shorter duration than adult only studies $(95 \% \mathrm{CI}$ 1.7 to $10.0 ; \mathrm{p}=0.040 ; \mathrm{SE}(\mathrm{p})=0.003)$. A second univariate RE meta-regression model suggested that there was non-significant increased mean duration of 4.0 days $\left(95 \%\right.$ CI $-0.6-8.6 ; \mathrm{p}=0.111 ; \mathrm{SE}(\mathrm{p})=0.005$; adj. $\mathrm{R}^{2}=22.0 \%$; $\mathrm{n}=14$ ) for studies that included moderate-severe or severe cases, relative to mild or mild-moderate severity cases.

High transmissibility during the first 5 days postsymptom onset was described by Cheng et $a l^{33}$ based on 
Table 3 Reported infectious period (IP) for postsymptomatic cases (T5 parameter) from virological studies where serial diagnostic tests were undertaken to infer IP (onset to $\geq 2$ tests); tracking studies where IP is inferred from patient histories from onset to recovery or death; modelling studies where IP is reported as a prior (assumed parameter value) or an posterior estimate

\begin{tabular}{lllll}
\hline Study & Location & $\begin{array}{l}\text { Parameter } \\
\text { (days) }\end{array}$ & $\begin{array}{l}\text { Central tendency } \\
\text { reported }\end{array}$ & $\begin{array}{l}\text { Variation } \\
\text { inclusion) }\end{array}$ \\
\hline $\begin{array}{l}\text { Virological studies } \\
\text { Cai et } a l^{76}\end{array}$ & China & 12 & Median & $6-22$ rang \\
Cai et $\mathrm{al}^{77}$ & China & 14 & Median & $9-19(\mathrm{IQR})$ \\
Chen et $a l^{78}$ & China & 12 & Max &
\end{tabular}

\begin{tabular}{lcclc}
\hline Cheng et $a l^{79}$ & China & 21 & Max & \\
Hu et $a l^{7}$ & China & 12 & Median & $12-14$ (IQR) \\
Kimball et $a l^{62}$ & Korea & 15.5 & Median & $14-17$ (range) \\
Kujawski et al ${ }^{43}$ & USA & 26 & Max & \\
& & & &
\end{tabular}

\section{Comment}

Serial testing study of $n=10$ mild cases RT-PCR confirmed in children. IQR: 8-15 days.

Serial testing study with $\mathrm{n}=298$ confirmed (RT-PCR) cases treated within hospital setting.

Single case study for a patient admitted to hospital where RT-PCR serial testing was undertaken. Patient had an additional positive test at day 17 but subsequently tested negative.

Case study of single patient serially tested by RT-PCR.

Serial testing study of patients who were first tested (qRT-PCR) when asymptomatic; this subset subsequently developed symptoms $(n=5)$.

$\begin{array}{llcl}\text { Lee et }\left.\mathrm{a}\right|^{80} & \text { Taiwan } & 20 & \text { Max } \\ \text { Lim et }\left.\mathrm{a}\right|^{44} & \begin{array}{l}\text { South } \\ \text { Korea }\end{array} & 16 & \text { Max }\end{array}$

\begin{tabular}{|c|c|c|c|c|c|}
\hline Ling et $\left.a\right|^{81}$ & China & 9.5 & Median & 2-22 (range) & $\begin{array}{l}\text { Serial testing of two confirmed cases } \\
\text { via RT-PCR. } n=66 \text {. IQR: } 6-11 \text { days, } \\
\text { oropharyngeal sampling. Mix of adult and } \\
\text { children. }\end{array}$ \\
\hline Marchand-Senécal et a/ ${ }^{45}$ & Canada & 23 & Max & & $\begin{array}{l}\text { Serial testing (RT-PCR) of a single patient } \\
\text { hospitalised presenting with pneumonia. }\end{array}$ \\
\hline Pan et al ${ }^{3}$ & China & 10 & Median & $8-12$ range & $\begin{array}{l}\text { Serial testing (RT-PCR) of two patients } \\
\text { hospitalised. Viral loads peaked days } 5-6 \\
\text { postonset. }\end{array}$ \\
\hline Qu et $a l^{83}$ & China & 22 & Max & & $\begin{array}{l}\text { Serial testing (RT-PCR) of a single patient } \\
\text { hospitalised. }\end{array}$ \\
\hline Tan et $a l^{46}$ & Vietnam & 16 & Max & & $\begin{array}{l}\text { Serial testing (RT-PCR) of a single patient } \\
\text { hospitalised; throat sample. }\end{array}$ \\
\hline Xing et $a^{69}$ & China & 14 & Median & & $\begin{array}{l}\text { Serial testing (RT-PCR) of three patients } \\
\text { (children) hospitalised. Mild-moderate } \\
\text { infection. Positive viral samples from } \\
\text { faeces up to } 4 \text { weeks postsymptom } \\
\text { onset. }\end{array}$ \\
\hline
\end{tabular}


Table 3 Continued



ICU, intensive care unit; RT-PCR, reverse transcriptase PCR. 


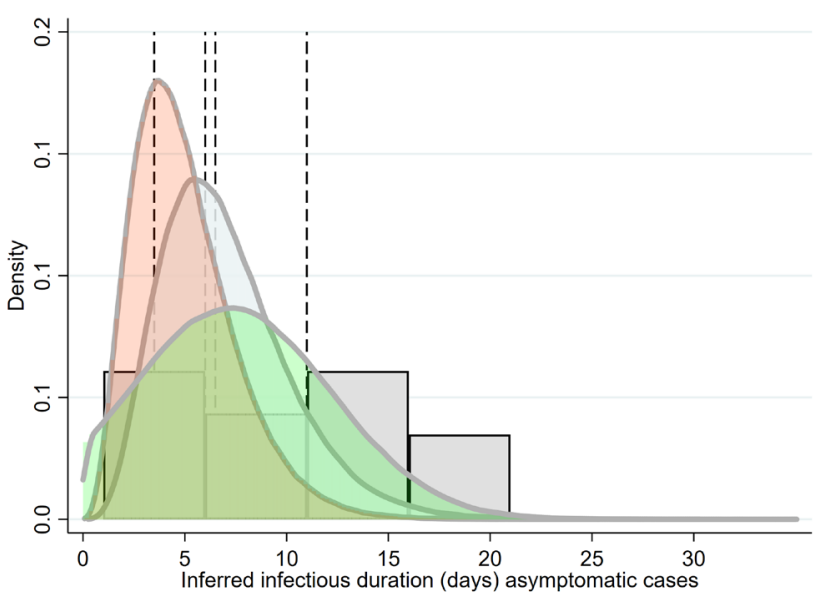

Figure 1 Simulation of the parameter distribution inferred for duration of infectious period for asymptomatic cases (T2); inferred infectious period for Davies et al, grey/blue curve, Davies et al pink curve (model priors). Green curve: Ma et al. Histogram is the distribution of asymptomatic cases to two clear tests reported by Hu et al. Reference lines are point estimates reported from Zhou et al, Li et al and Tuite et al. $^{78141526273971}$

secondary attack rates for 12 infector-infectee pairs. No contacts $(\mathrm{n}=1043)$ with primary cases were infected after 5 days of the index case onset of symptoms, inferred by the authors to suggest transmission occurring at symptom onset (but conceivably also suggest pre-symptomatic infection). Based on a cumulative density function, the authors suggest that infectiousness declines rapidly from onset of infection (distribution was truncated at 30 days); estimated cumulative infectiousness was $66.9 \%$ (95\% CI

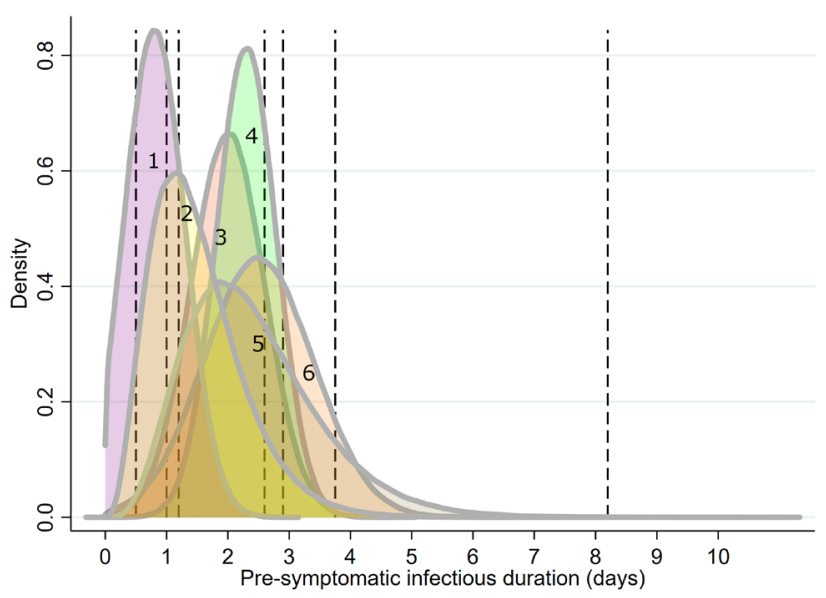

Figure 2 Simulation of the parameter distribution used for T3 (the duration of the pre-symptomatic infectious period for those infected individuals who subsequently develop symptoms). Curves represent simulated approximations of distributions, given information provided from primary literature. Vertical lines represent point estimates where distributions could not be inferred (see table 2). 1. Peak et al (posterior); 2. Davies et al(prior); 3. Rothe et al; 4. He et al; 5. Davies et al (prior); 6. Wei et al. ${ }^{91415293032}$

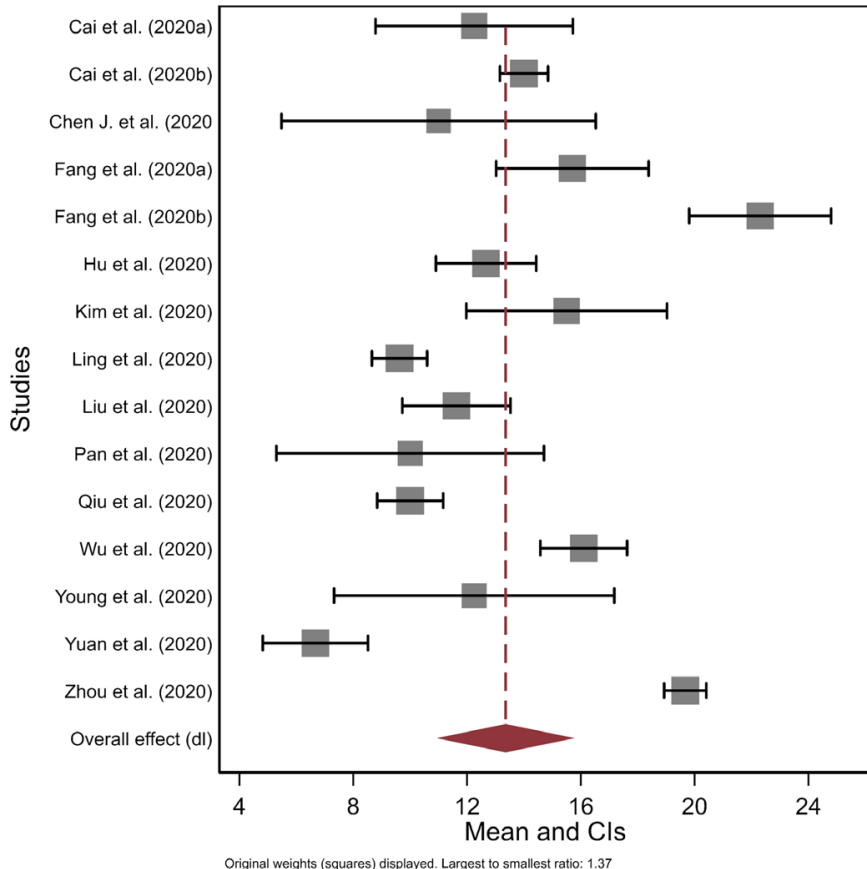

Figure 3 Forest plot of the mean duration from onset of symptoms to death or recovery (T5) based on virological studies.

28.7 to 94.8 ) by day 1 and reached $86.9 \%$ (95\% CI 64.3 to 99.5 ) by day five postsymptom onset (online supplementary figure S2).

For tracking studies relating to time to hospital discharge or death, raw case level data were available (studies $\mathrm{n}=3$ ). ${ }^{31}{ }^{34-36}$ Histograms of the raw data are presented in figure 4, along with the aggregated distribution. An RE model suggested a mean duration of 18.1 days (95\% CI 15.1 to 21.0). However, there was significant variation across studies, with time to discharge being 4.96 days shorter (95\% CI 2.15 to $7.76^{35}$ ) or 3.79 days shorter $\left(95 \%\right.$ CI 0.8 to $\left.6.7^{31}\right)$ than time to death. ${ }^{34}$

Two modelling papers use priors (mean: 3.2-3.5 days) to represent clinical infectious period. ${ }^{14}{ }^{15}$ However, the distribution for this parameter is right censored when patients are hospitalised or isolated and therefore not an estimate of the full infectious period per se.

\section{Infectious period for symptomatic cases (T3+T5)}

Two tracing studies supplied parameter estimates for the full infectious period for patients who develop symptoms. ${ }^{8} 29 \mathrm{He}$ et $a l^{29}$ inferred from a publicly available dataset of 77 infector-infectee pairs that infectiousness began 2.3 days (95\% CI 0.8 to 3.0 days) prior to symptom onset, peaking at 0.7 days (95\% CI -0.2 to 2.0 days) and continued up to 7 days from onset. The authors suggest that the transmission risk diminishes 7 days postsymptom onset. This suggests that the average infectious period, assuming a symptomatic infectious period of 7 days was approximately 9.3 days (95\% CI 7.8-10 days, where CI is only reported for the presymptomatic period). He $e t a l^{29}$ estimated that the proportion of all transmission that was presymptomatic was $44 \%$ (95\% CI $25 \%$ to 


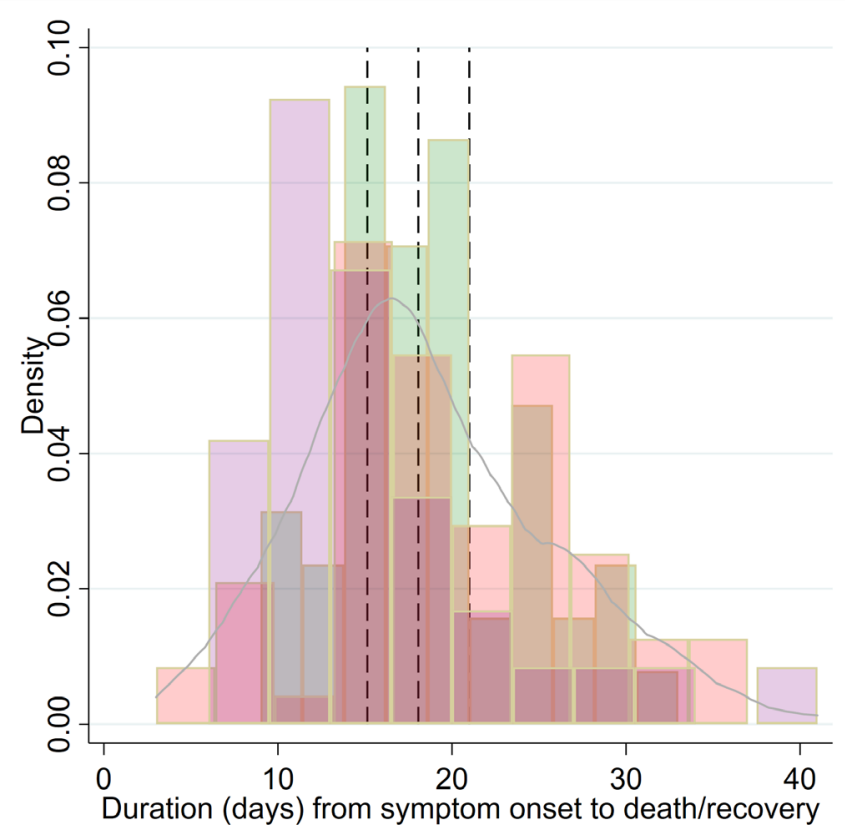

Figure 4 Frequency distribution of T5, time from onset of symptoms to recovery (here hospital discharge or death), using patient level raw data from Kraemer et $a^{3536}$ (pink bars), Linton et $\left.a\right|^{34}$ (purple bars) and Tindale et $\left.a\right|^{31}$ (green bars). Blue solid line is the kernel density of the aggregated dataset. Dashed lines represent the mean and $95 \% \mathrm{Cl}$ from a random effects regression model.

$69 \%)$. Ma $e t a l^{8}$ analysed data from a number of countries (China, Germany, Japan, Malaysia, Singapore and Vietnam), collating 1155 cases from public data. They estimate several parameters, including 'maximum latent period' and the serial interval. The authors estimated the infectious period as maximum latent period minus the serial interval. Given their parameter estimates and methodological approach, infectious period would have been 5 days (range 0-24; IQR: 2-9; calculated from data presented within the paper).

Seven modelling papers reported duration of infectious period (T3+T5; table 4), with the reported central tendency for the distribution varying from 3 to 20 days. The form of the distribution offered to models for this parameter varied considerably, including point estimates (deterministic models), flat (uniform), Gaussian, Weibull and gamma distributions. Li $e t a l^{27}$ estimated the shortest median duration of 3.45 days, with a flat (uninformative) prior distribution corralled between $3-5$ days. In contrast, $\mathrm{Zhu}^{37}$ used a mean prior of 10 days, with the model estimated mean duration being 12.5 days (variance 10; Weibull distribution). Piccolomiini and Zama ${ }^{38}$ used a fixed estimate of 20-day infectious period to model the Italian epidemic. Two papers from the same group ${ }^{145}$ suggested that infectious period for asymptomatic cases approximated for symptomatic cases where there was no right censoring (ie, transmission being halted through isolation or hospitalisation; gamma distributions of mean
5 or 7 days). Tuite $e t a l^{2639}$ also assumed the same duration for 'mild' and 'severe' symptomatic cases (6-6.5 days).

\section{Viral load dynamics}

Viral load was reported from 21 papers using realtime RT-PCR testing, generally postsymptomatic monitoring. ${ }^{3} 29-59$ Qualitatively, the viral dynamics described early increase in viral load, peaking around onset or within 2-4 days of symptom onset (figure 5 for a theoretical model), before decreasing gradually over the next $1-3$ weeks postsymptom onset. Maximum duration of detection ranged from approximately 20-49 days, with the longest duration associated with faecal samples (see Discussion). The duration where RNA was recoverable by RT-PCR may have been truncated due to insufficient follow-up in some cases. Studies that have investigated blood samples have provided some evidence for an association with severity of infection, ${ }^{160}$ though it is not clear whether this is a consistent feature of SARS-CoV-2 infection. ${ }^{40}$

It should be noted the lack of data on presymptomatic or asymptomatic cases with regards viral load. An exception was Kam $e t a l,{ }^{61}$ who describe a presymptomatic case in an infant. In another study, Zou et $a{ }^{53}$ undertook serial RT-PCR testing from nasal and throat swab samples from 14 imported cases and 4 secondary cases, in Guangdong, China. The dynamics of the infection in terms of $\mathrm{Ct}$ values and RNA copy number were described; Ct values of 30.76 , $27.67,24.56$ and 21.48 corresponding to $1.5 \times 10^{4}, 1.5 \times 10^{5}$, $1.5 \times 10^{6}$ and $1.5 \times 10^{7}$ copies per millilitre. Hence, lower $\mathrm{Ct}$ values infer higher viral loads. The authors report on a patient without symptoms, but with positive nasal swabs (Ct values: 22-28) and throat swabs (Ct values: 30-32) testing positive on days 7, 10 and 11 after contact. Importantly, the authors suggest 'the viral load that was detected in the asymptomatic patient was similar to that in the symptomatic patients'. Furthermore, Kimbell et a ${ }^{62}$ report that Ct values between asymptomatic (21.9-31.0), presymptomatic (15.3-37.9) and symptomatic cases (18.6-29.2) within a nursing home environment did not differ significantly. To et $a \tilde{l}^{9}$ present data on temporal profile of viral load from saliva samples and found that median initial and peak viral loads in severe cases were non-significantly higher $(p>0.5)$ by approximately $1 \log 10$ higher than those in mild cases. Liu et $a \tilde{p}^{58}$ present data showing viral load being 60 times greater for severe cases relative to mild cases.

This lack of presymptomatic data may result in left truncation of the risk distribution associated with viral load and shedding. Therefore, the typical timing of peak viral shedding (whether prior to, at or after onset), and its impact on transmission, is still uncertain. He et $a l^{29}$ reported highest viral load at symptom onset from patients sampled in a hospital in China. Furthermore, the author's estimate using a separate infector-infectee dataset $(n=77)$ that $44 \%(95 \%$ CI $25 \%$ to $69 \%)$ of infectee cases were infected during the presymptomatic stage of the infector. Separately, a modelling paper by Ferretti et $a l^{63}$ also appears to support this, estimating that $47 \%(0.9 / 2)$ of total transmission contributing $\mathbf{R}_{0}$, an 
Table 4 Reported infectious period (IP) for symptomatic cases (T3+T5 parameter) from virological studies where serial diagnostic tests were undertaken to infer IP (exposure to $\geq 2$ neg. tests); tracking studies where IP is inferred from patient histories from onset to recovery or death; modelling studies where IP is reported as a prior (assumed parameter value) or an posterior estimate

\begin{tabular}{|c|c|c|c|c|c|}
\hline Study & Location & $\begin{array}{l}\text { Parameter } \\
\text { (days) }\end{array}$ & $\begin{array}{l}\text { Central } \\
\text { tendency } \\
\text { reported }\end{array}$ & $\begin{array}{l}\text { Variation (days; } \\
\text { inclusion) }\end{array}$ & Comment \\
\hline \multicolumn{6}{|l|}{ Tracking studies } \\
\hline Ma et $a l^{8}$ & Various & $\sim 5$ days & Median & Range 0-24 & $\begin{array}{l}\text { The authors estimated the infectious period as latent minus the } \\
\text { serial interval, using a dataset of } 1155 \text { cases. Range 0-24; IQR: } \\
\text { 2-9; calculated from data presented within the paper. }\end{array}$ \\
\hline \multicolumn{6}{|c|}{ Modelling studies } \\
\hline Li et $a l^{27}$ & China & $\begin{array}{l}3.45 \text { days } \\
\text { (posterior } \\
\text { estimated } \\
\text { from model for } \\
\text { documented } \\
\text { cases) }\end{array}$ & Median & $\begin{array}{l}95 \% \mathrm{Cl} \text { for the } \\
\text { mean: } 3.19,3.72\end{array}$ & $\begin{array}{l}\text { Mathematical model. Priors for mean documented infectious } \\
\text { period was a flat (uniform) distribution } 2-5 \text {. 'Documented' } \\
\text { cases were defined as those severe enough to be confirmed. } \\
\text { This corralling of the infectious period relative to other studies } \\
\text { should take into account that the distribution is used for the } \\
\text { central tendency, not the whole distribution. }\end{array}$ \\
\hline Tuite et $a l^{2639}$ & Canada & $\begin{array}{l}6-6.5 \text { days } \\
\text { (prior; fixed } \\
\text { parameter within } \\
\text { a deterministic } \\
\text { model) }\end{array}$ & $\begin{array}{l}\text { Fixed } \\
\text { parameter }\end{array}$ & & $\begin{array}{l}\text { Mathematical model (deterministic), with a fixed parameter } \\
\text { estimate of } 6.5 \text { days (a) and } 6 \text { days (b), respectively. Important } \\
\text { to note that duration for 'mild' was equal to severe cases. }\end{array}$ \\
\hline Lourenço et $a l^{89}$ & UK & $\begin{array}{l}\text { 3-5 days } \\
\text { (posterior; } \\
\text { approximate } \\
\text { depending on } \\
\text { scenario tested) }\end{array}$ & Mean & $\begin{array}{l}95 \% \mathrm{Cl} \text { of 3-6 } \\
\text { days }\end{array}$ & $\begin{array}{l}\text { Mathematical model. The prior used was given a Gaussian } \\
\text { distribution (normal curve); mean 4.5; SD 1; approximate } \\
95 \% \mathrm{Cl} \text { of } 3-6 \text { days. } \\
\text { The reported posterior of this parameter was presented } \\
\text { graphically and depended on } \mathrm{RO} \text { and proportion at risk. } \\
\text { Depending on the scenarios tested, mean duration of } \\
\text { infectiousness appeared to vary from } 3 \text { to } 5 \text { days. }\end{array}$ \\
\hline Zhu et al ${ }^{37}$ & Wuhan, China & $\begin{array}{l}12.5 \text { days } \\
\text { (posterior } \\
\text { estimated from } \\
\text { model) }\end{array}$ & Mean & 11.4 variance & $\begin{array}{l}\text { Mathematical model. The parameter was estimated using } \\
\text { a Weibull distribution. The prior for this parameter was } 10 \\
\text { days. The posterior variance around the mean was } 11.4 \text {, and } \\
\text { therefore the distribution had a long tail. This study was a } \\
\text { modelling (SEIR extended model). }\end{array}$ \\
\hline Davies et $a l^{14}$ & UK & 5 days (prior) & Mean & & $\begin{array}{l}\text { Model with asymptomatic infection compartment. Modelled } \\
\text { with a gamma distribution, } \mathrm{k}=4 \text {. Authors: 'Assumed to be the } \\
\text { same duration as total infectious period for clinical cases, } \\
\text { including preclinical transmission'. }\end{array}$ \\
\hline $\begin{array}{l}\text { Piccolomini } \\
\text { and Zama }\end{array}$ & Italy & 20 days (prior) & Fixed & & $\begin{array}{l}\text { Parameter estimate assumed for the infectious period within an } \\
\text { SEIRD Susceptible, Exposed, Infectious, Recovered and Dead) } \\
\text { model, fitted to data from the epidemic in Italy. }\end{array}$ \\
\hline
\end{tabular}

${ }^{*} 95 \% \mathrm{Cl}$ from presymptom infectious period only.

overall measure of transmission during an infection, was presymptomatic (also see ref 33).

Wölfel et a $a \tilde{l}^{0}$ provides important data on a cohort of nine 'mild' cases that were serially tested using sputum, swabs (throat and nasopharyngeal), urine and faecal samples over time. Importantly, the virus was isolated, and inferences on viral replication could be made. Viral isolation and insights into viral replication improve inference around viral dynamics and transmission risk. The study suggested high viral loads shortly after symptom onset, which declined thereafter over time. Positive cultures were found from day 3-8 postsymptom onset (online supplementary figure S3), and the minimum $5 \%$ isolation success was achieved up to 9.8 (95\% CI 8.5 to 21.8$)$ days postonset from throat and lung samples but not faeces, blood or urine.

\section{DISCUSSION}

Inferring infectiousness was challenging given the heterogeneity of evidence available. Virological diagnostic studies provide robust time series of infection; however, 


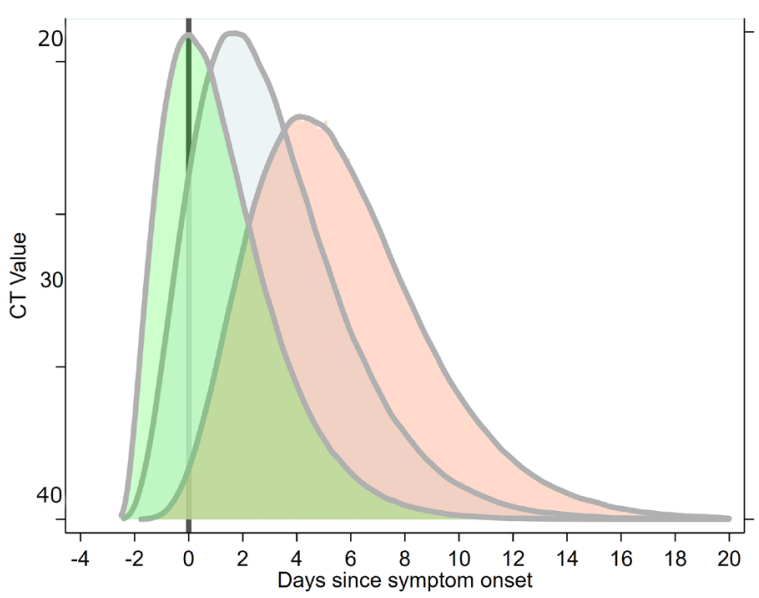

Figure 5 Composite inferred model for cycle threshold (CT) value changes from serial RT-PCR testing for SARSCoV-2; currently uncertain whether peak viral load typically occurs prior to, on or postsymptom onset (primary literature informing this model includes. ${ }^{29} 505359$ SARS-CoV-2, severe acute respiratory syndrome coronavirus 2 .

it is limited by inferring the relationship between PCR diagnostics and infectiousness. These data can also be affected by sampling procedure and sample sites (eg, upper respiratory, lower respiratory, faeces, urine and blood). We have excluded RT-PCR durations based on faecal sampling due to the current uncertainty whether these data pertain to transmission potential. ${ }^{50}$. Virological studies where culturing has taken place and where viral replication can be inferred would also be considered superior data to infer infectious period, relative to estimates of viral load alone. ${ }^{50}$ Where this has taken place, the data would suggest average infectious periods of up to 9.8 days postsymptoms. Recent modelling work suggest that the duration of viral detectability could overestimate the infectious period somewhere between 2 and 6 days. ${ }^{64}$

Viral load studies suggest peak viral load occurs close to symptom onset (potentially, -1 to 7 days of onset); however, there is uncertainty whether this typically occurs prior to, on or after onset (figure 5 for conceptual model). High viral loads, measured as Ct values, have been recorded for 1 week to 20 days postsymptom onset, with a general decreasing trend with time. For example, To et $a \tilde{l}^{\tilde{9}}$ estimates a declining slope per day for $\log 10$ RNA copies per $\mathrm{mL}$ of $-0 \cdot 15$ (95\% CI $-0 \cdot 19$ to $-0 \cdot 11$; $\left.R^{2}=0 \cdot 71\right)$. There are some studies reporting associations between viral load and symptom severity, with higher metrics of viral load in severe cases. ${ }^{358}{ }^{59}$ However, Zou et $a l,{ }^{53}$ and more recent data from Italy, ${ }^{64} 65$ suggest similar viral loads in symptomatic and asymptomatic cases.

We tested the hypothesis that severity of symptoms had an effect on symptomatic infectious duration using a meta-regression approach. There was a trend towards studies that included severe cases having longer duration (estimated to be 4.0 days longer), but the effect was not significant. Some studies have reported an association between duration of infectiousness and severity (eg, ref 58). However, uncertainty of whether this is robust remains. Caution is required when comparing severity of symptoms, as objective or standardised metrics are not always reported.

Virological studies that included children (either mixed adult children or children only cohorts) appeared to have shorter T5 durations (estimate: 5.8 days shorter). Liao et $a l^{66}$ present data that suggests that children and 'young adults' ( $<35$ years old) infected cases exhibited long incubation time (exposure to symptom onset; mean 7.2 days) and short serial interval (mean 6.5 days; median 1.9 days; time from onset in primary to onset in secondary case).

Contact tracing studies provided robust evidence of transmission events, and therefore infectiousness, but can be limited by the inferred timing of events, and symptoms experienced, due to the self-reported nature of data collection (recall bias). The subjective nature of self-reporting indeed can have an impact on case definitions of 'asymptomatic', which has led to some doubt on asymptomatic transmission in one case. ${ }^{9}$ Rothe $e t$ a ${ }^{9}$ describe a case of apparent asymptomatic transmission from a Chinese visitor to business associates in Germany, which was cast into doubt when health officials reported that the patient had indeed experienced some, although minor, symptoms. ${ }^{67}$ Rothe $e t a t$ subsequently updated the clarification of the patients self-reported symptoms during the presumed asymptomatic infectious period, which included 'feeling warm' and 'feeling cold'. However, the patient only 'recognized getting sick' after she returned to China on day four after the presumed exposure event.

Modelling parameters provide information on how COVID-19 data are being used and interpreted in the research community, given the limited data available. Posterior estimates also provide information on the parameter space at which infectious period central tendency reside, given other parameters and assumptions in the model. Models used highly varied approaches to modelling infectious period, which in turn resulted in highly variable parameter estimates used to inform the studies. An important factor to consider when comparing parameter estimates between empirical and modelling studies is the interpretation of the parameter by different disciplines and even between researchers from the same discipline. The infectious period can be considered significantly context specific and dynamic, and the ability to transmit infection can be modulated by interventions (eg, through isolation or hospitalisation). Modelling papers, depending on the model structure, can report truncated infectious period accounting for such interventions. Such estimates are not comparable with our definition of the parameters reviewed, and we have attempted to avoid such disparities where we found them.

\section{Overall duration findings}

There are few data for the precise definition of the asymptomatic infectious period (T2) parameter. Some reported asymptomatic cases can actually be presymptomatic, when 
cases are subject to follow-up (eg, ref 66; see Discussion). However, Hu $e t a l^{7}$ do provide the data for asymptomatic cases (that remain asymptomatic) across their presumed infectious period. Therefore, in the first instance, a parameter mimicking their data is probably the best available data over the period of the present study. Note there is a large variation in this data parameter, and a gamma distribution of a shape alpha 3 , beta 2 , mean 6 , may be appropriate for the initial model runs. Despite these being the primary informative data, caution is required, given the uncertainty around the relationship between RT-PCR results and infectiousness. Overall, an informed central tendency of $\sim 6$ days, with very low probability draws for durations $>20$ days for the T2 parameter may be considered given the current state of knowledge.

The presymptomatic period is sometimes referred to as 'preclinical infectious' period (parameter T3). This has been estimated from several papers, and the central tendency of these estimates vary from $<1$ to 4 days, cautiously approximating to 2 days, on average. Current models have used central tendency estimates of 0.5-2.4 days. ${ }^{14152639}$ The relative consistency around the duration of this period allows for some confidence of its distribution. Current understanding of viral dynamics of infection suggest that viral load and shedding increases during postlatent phase, peaking around onset (for symptomatic cases), before declining. ${ }^{29} 5053$ This aspect of the natural history of infection may be important when attempting to model transmission dynamics.

Length of infectious period in symptomatic cases that do not isolate ( 55 parameter) has also been rarely directly measured in the literature, as serial monitoring of patients in terms of symptoms or viral load (RT-PCR) generally occurs after diagnosis and/or after admission to hospital (from a modelling perspective, this means cases are censored as they are assumed to no longer contribute to transmission). If natural progression of infection after diagnosis or hospital admission mimics the course of infection for those who do not isolate, the review of the literature describing time to two clear tests is informative. Symptom onset to serial testing clearance (assessed the time to first of two RT-PCR clear tests) averaged 13.4 days from our meta-analysis. In the maximal case, where patients succumb or fully recover from infection, time from symptoms to death or discharge may be informative. Studies that collated such information suggest mean durations of 18.07 days but with time to discharge being 4.96 days shorter on average than time to death. These values may represent an overestimation of the infectious period; one study suggested that there was on average 2.5 days between end of infectiousness and 'removal' (recovery or death). ${ }^{37}$

Cheng $e t a l^{33}$ provided evidence of transmissibility, based on attack rate from primary to secondary cases, at around symptom onset. The authors estimate cumulative infectiousness from onset, which suggests that $67 \%$ of total infectiousness potential occurs by the first day postonset. Most of the total infectiousness occurs within
5 days $(86.9 \%)$ postonset, with the remaining infectiousness potential (13.1\%) being distributed up to day 30 (this truncation is an assumption by the authors). It is possible that presymptomatic transmission occurred during this study, but the authors do not estimate what proportion of transmissions occurred during a presymptomatic infectious period or its potential duration.

A model by He $e t a l^{29}$ is informative for overall symptomatic duration $(\mathrm{T} 3+\mathrm{T} 5)$, using 77 infector-infectee pairs where COVID-19 transmission occurred in China. The study reported that infectiousness was apparent on average 2.5 days prior to symptoms, reached a peak in risk at 0.6 days before symptoms and decline up until 7 days after onset (9.5 days total infectious period). The proportion of transmission before symptom onset (area under the curve) was estimated as $44 \%$ (95\% CI $25 \%$ to $69 \%$ ) based on inferences on incubation period. The authors suggest their data supported the view that transmission risk decline substantially after 7 days postsymptoms onset.

Model estimates used for infectious period parameter appears to be shorter than virological studies tracking RNA viral load over time. For example, Li $e t a l^{27}$ fitted a flat prior distribution for mean duration $(D)$ fixed to vary between: $2 \leq D \leq 5$ days, and Lavezzo $e t a l^{64}$ fixed infectious period to 2 days in their epidemic model, whereas viral repeat testing studies provide evidence to suggest high viral loads can be detected to up 20 days (eg, pharyngeal swabs) and potentially longer from faecal samples (3-4 weeks or longer postsymptom onset)). Oral-faecal transmission risk is currently unknown, but some doubt has been raised about studies that have reported positive RT-PCR test results (see ref 68; but there may be some evidence of the risk among children ${ }^{69}$ ). Wölfel et $a \rho^{50}$ has produced an important study that provides some data on viral replication and the site and duration over which this may be taking place. Their data suggest that viral replication, with high viral loads, occur in the upper respiratory tract, over the first week of symptoms peaking in day 4 . Virus could not be isolated from faecal samples, despite high RNA concentration. Furthermore, virus was not isolated from blood or urine in that study. ${ }^{50}$

It should be noted that some of the virological and tracing studies reviewed had small sample sizes (see Study limitations) and potentially biased towards more severe cases or clusters of infection. It is unknown as to whether these cases are representative of infectious duration generally across populations. However, if symptom severity is linked to infectious duration, one could speculate that this bias could help to explain the some of the difference between model and empirical duration estimates.

\section{Study limitations}

Overall, the studies included were of good quality, though due to the rapid need for information from the global research community, many papers are preprints that have yet to be reviewed (at time of writing). Many papers were limited in terms of sample sizes, with several papers being case studies of one patient or single cluster outbreaks. There 
was a diversity of methods employed to infer dynamics of infectiousness across studies, and therefore the evidential base was variable. Some issues around nomenclature were noted, including definitions of asymptomatic, infectious period, latent and incubation period. It is possible the same data may have been used across different studies, especially where publicly available data were used.

There was significant heterogeneity across study findings, and this was related to diversity of clinical findings and methods employed. The meta-analysis employed for one parameter (T5) using virological studies, where cross-study comparisons could be made, suggested that the heterogeneity was high. Fu et $a l^{70}$ cautions against combining studies to give an overall estimate without exploring subgroup or meta-regression analysis, which we have done here. The meta-regression was based on a small number of studies $(\mathrm{n}=12-13)$. Cochrane's handbook suggests 10 studies for each level of a meta-regression; however, in practice much lower numbers have been used to test hypotheses, ${ }^{22}$ as is the case here. Fu et $a l^{70}$ recommend a minimum of four studies per category, and therefore we dichotomised our predictor variables to ensure we met this minimum. Aggregating our categories resulted in crude findings.

Another limitation is that a systematic review was not undertaken to inform this research, hence there is a possibility that some relevant studies were overlooked. However, two independent research groups conducted comprehensive search strategies as part of a broader epidemiological parameters project for COVID-19 $9^{12}{ }^{13-73}$ to inform this research, hence limiting the potential for missing key studies.

\section{CONCLUSION}

There are few data to inform asymptomatic infectious period (T2 parameter). One study provide data that suggest a median period of 4-9.5 days; however, given the viral dynamics, this distribution could have an extended tail with low probability long infectious periods of up to 20 days. The presymptomatic infectious phase (T3) is quite narrowly defined to a mean of approximately 2 days (range: $<1-4)$ within the literature. However, there is great uncertainty around the infectious period from onset to recovery or death (T5 parameter). The symptom onset until clearance (based on two negative RT-PCR tests) parameter estimate of 13.4 days (95\% CI 10.9 to 15.8) is informative for T5 parameter, only if one assumes that RT-PCR positive results equate to having infectious potential. Many current models corral the infectious period to shorter time periods than what virological studies have suggested, with one recent study suggesting that duration of viral detectability overestimates the infectious period on average by $2-6$ days. While viral RNA can be detected for long periods of time, especially from faecal samples, the ability to isolate the virus from infected cases quickly declines after 1-week postsymptoms. Some modelling papers have assumed that infectious period is invariant to whether cases are asymptomatic or symptomatic; however, the data available are not yet rich enough to inform whether this is a good assumption. Similarly, it is not yet established whether viral loads are similar between asymptomatic and mild, moderate or severe symptomatic cases, with conflicting reports in the literature.

\section{Author affiliations}

${ }^{1}$ One-Health Scientific Support Unit, Government of Ireland Department of Agriculture Food and the Marine, Dublin, Ireland

${ }^{2}$ School of Public Health, Physiotherapy and Sports Science, University College Dublin, Dublin, Ireland

${ }^{3}$ Centre for Veterinary Epidemiology and Risk Analysis, School of Veterinary Medicine, University College Dublin, Dublin, Ireland

${ }^{4}$ Government of Ireland Department of Agriculture Food and the Marine, Dublin, Ireland

${ }^{5}$ Centre for Food Safety, School of Biosystems and Food Engineering, University College Dublin, Dublin, Ireland

${ }^{6}$ School of Veterinary Medicine, University College Dublin, Dublin, Ireland ${ }^{7}$ Health Information and Quality Authority, Cork, Munster, Ireland

${ }^{8}$ Department of Public Health, School of Public Health, Physiotherapy and Sports Science, University College Dublin, Dublin, Ireland

Twitter Andrew William Byrne @AndyByrneSci, Miriam Casey @MiriamC51755360 and Kieran A Walsh @kieranwalshmpsi

Contributors AWB conducted the eligibility screening of shortlisted studies, extracted the data and conducted the analyses and completed the initial draft of the manuscript; SM was involved in conception and project coordination; ÁBC, KH and $\mathrm{FB}$ conducted the initial literature searches; DM, KOB and KAW conducted searches and screened shortlisted studies; AWB, SJM, ÁBC, KH, FB, DM, KOB, KAW, AB, JG, EAL, PW, CM and MC critically reviewed and commented/edited the paper. All authors read and approved the final manuscript.

Funding The authors have not declared a specific grant for this research from any funding agency in the public, commercial or not-for-profit sectors.

Competing interests None declared.

Patient and public involvement Patients and/or the public were not involved in the design, or conduct, or reporting, or dissemination plans of this research.

Patient consent for publication Not required.

Provenance and peer review Not commissioned; externally peer reviewed.

Data availability statement All data relevant to the study are included in the article or uploaded as supplementary information. The data used in this paper and code are presented in supplementary material 2 and 3; no additional data available.

Open access This is an open access article distributed in accordance with the Creative Commons Attribution Non Commercial (CC BY-NC 4.0) license, which permits others to distribute, remix, adapt, build upon this work non-commercially, and license their derivative works on different terms, provided the original work is properly cited, appropriate credit is given, any changes made indicated, and the use is non-commercial. See: http://creativecommons.org/licenses/by-nc/4.0/.

\section{ORCID iDs}

Andrew William Byrne http://orcid.org/0000-0003-0296-4586

David McEvoy http://orcid.org/0000-0002-9057-2779

Miriam Casey http://orcid.org/0000-0002-9057-2779

John Griffin http://orcid.org/0000-0001-7509-6770

Conor McAloon http://orcid.org/0000-0002-4984-4031

\section{REFERENCES}

1 Wu F, Zhao S, Yu B, et al. A new coronavirus associated with human respiratory disease in China. Nature 2020;579:265-9.

2 Li Q, Guan X, Wu P, et al. Early transmission dynamics in Wuhan, China, of novel coronavirus-infected pneumonia. N Engl J Med 2020;382:1199-207.

3 Pan Y, Zhang D, Yang P, et al. Viral load of SARS-CoV-2 in clinical samples. Lancet Infect Dis 2020;20:411-2.

4 Huang C, Wang Y, Li X, et al. Clinical features of patients infected with 2019 novel coronavirus in Wuhan, China. Lancet 2020;395:497-506. 
5 Russell TW, Hellewell J, Jarvis Cl, et al. Estimating the infection and case fatality ratio for coronavirus disease (COVID-19) using age-adjusted data from the outbreak on the diamond Princess cruise SHIP, February 2020. Euro Surveill 2020;25:2000256.

6 Onder G, Rezza G, Brusaferro S. Case-fatality rate and characteristics of patients dying in relation to COVID-19 in Italy. JAMA 2020;323:1775-6.

$7 \mathrm{Hu} \mathrm{Z}$, Song C, Xu C, et al. Clinical characteristics of 24 asymptomatic infections with COVID-19 screened among close contacts in Nanjing, China. Sci China Life Sci 2020;63:706-11.

$8 \mathrm{Ma} \mathrm{S}$, Zhang J, Zeng M, et al. Epidemiological parameters of coronavirus disease 2019: a pooled analysis of publicly reported individual data of 1155 cases from seven countries. medRxiv 2020

9 Rothe C, Schunk M, Sothmann P, et al. Transmission of 2019-nCoV infection from an asymptomatic contact in Germany. N Engl J Med 2020;382:970-1.

10 Bai Y, Yao L, Wei T, et al. Presumed asymptomatic carrier transmission of COVID-19. JAMA 2020;323:1406-7.

11 Anderson RM, Heesterbeek $\mathrm{H}$, Klinkenberg D, et al. How will countrybased mitigation measures influence the course of the COVID-19 epidemic? Lancet 2020;395:931-4.

12 Casey M, Griffin J, McAloon CG, et al. Estimating pre-symptomatic transmission of COVID-19: a secondary analysis using published data. medRxiv 2020.

13 IEMAG Epidemiology Modelling subgroup. COVID-19 epidemiological parameters summary document, 2020. Available: https://www.gov.ie/en/publication/dc5711-irish-epidemiologymodelling-advisory-group-to-nphet-technical-notes/

14 Davies NG, Klepac P, Liu Y, et al. Age-dependent effects in the transmission and control of COVID-19 epidemics. Nat Med 2020. doi:10.1038/s41591-020-0962-9. [Epub ahead of print: 16 Jun 2020].

15 Davies NG, Kucharski AJ, Eggo RM, et al. Effects of nonpharmaceutical interventions on COVID-19 cases, deaths, and demand for hospital services in the UK: a modelling study. Lancet Public Health 2020;5:e375-e385.

16 HIQA. Evidence summary for COVID-19 viral load over course of infection. health information and quality authority, Ireland, 2020. Available: https://www.hiqa.ie/reports-and-publications/healthtechnology-assessment/evidence-summary-covid-19-viral-load-over [Accessed 1 Apr 2020].

17 HIQA. Evidence summary for asymptomatic transmission of COVID-19. health information and quality authority, Ireland. Available: https://www.hiqa.ie/reports-and-publications/health-technologyassessment/evidence-summary-asymptomatic-transmission [Accessed 1 apr 2020].

18 HIQA. Protocol for evidence synthesis support - COVID-19. health information and quality authority, Ireland, 2020. Available: https:// www.hiqa.ie/sites/default/files/2020-04/Protocol-for-HIQA-COVID19-evidence-synthesis-support 1-2.pdf.pdf [Accessed 1 Apr 2020]

19 Munn Z, Peters MDJ, Stern C, et al. Systematic review or scoping review? guidance for authors when choosing between a systematic or scoping review approach. BMC Med Res Methodol 2018;18:143.

20 Tricco AC, Langlois EV, Straus SE. Rapid reviews to strengthen health policy and systems: a practical guide. World Health Organization Geneva, 2017.

21 Wan X, Wang W, Liu J, et al. Estimating the sample mean and standard deviation from the sample size, median, range and/or interquartile range. BMC Med Res Methodol 2014;14:135.

22 Higgins JP, Thomas J, Chandler J, et al. Cochrane handbook for systematic reviews of interventions. John Wiley \& Sons, 2019.

23 Brockwell SE, Gordon IR. A comparison of statistical methods for meta-analysis. Stat Med 2001;20:825-40.

24 Higgins JPT, Thompson SG, Deeks JJ, et al. Measuring inconsistency in meta-analyses. BMJ 2003;327:557-60.

25 Higgins JPT, Thompson SG. Controlling the risk of spurious findings from meta-regression. Stat Med 2004;23:1663-82.

26 Tuite AR, Fisman DN, Greer AL. Mathematical modelling of COVID-19 transmission and mitigation strategies in the population of Ontario, Canada. CMAJ 2020;192:E497-505.

27 Li R, Pei S, Chen B, et al. Substantial undocumented infection facilitates the rapid dissemination of novel coronavirus (SARSCoV-2). Science 2020;368:489-93.

28 Hoehl S, Rabenau H, Berger A, et al. Evidence of SARS-CoV-2 infection in returning travelers from Wuhan, China. N Engl $J$ Med 2020;382:1278-80.

29 He X, Lau EHY, Wu P, et al. Temporal dynamics in viral shedding and transmissibility of COVID-19. Nat Med 2020;26:672-5.

30 Wei WE, Li Z, Chiew CJ, et al. Presymptomatic Transmission of SARS-CoV-2 - Singapore, January 23-March 16, 2020. MMWR Morb Mortal Wkly Rep 2020;69:411-5.
31 Tindale L, Wallinga J, Coombe M, et al. Transmission interval estimates suggest pre-symptomatic spread of COVID-19. Available: https://www medrxiv org/content/101101/202003 0320029983 v1 2020

32 Peak CM, Kahn R, Grad YH, et al. Comparative impact of individual quarantine vs. active monitoring of contacts for the mitigation of COVID-19: a modelling study. medRxiv 2020. doi:10.1101/2020.03.0 5.20031088. [Epub ahead of print: 08 Mar 2020]

33 Cheng $\mathrm{H}-\mathrm{Y}$, Jian S-W, Liu D-P, et al. High transmissibility of COVID-19 near symptom onset. medRxiv 2020

34 Linton NM, Kobayashi T, Yang Y, et al. Incubation period and other epidemiological characteristics of 2019 novel coronavirus infections with right truncation: a statistical analysis of publicly available case data. J Clin Med 2020;9:538.

35 Kramer M, Pigott D, Xu B, et al. Epidemiological data from the $n \mathrm{CoV}$ 2019 Outbreak: Early Descriptions from Publicly, 2020. Available: https://virological.org/t/epidemiological-data-from-the-ncov-2019outbreak-early-descriptions-from-publicly-available-data/337 [Accessed 29 Mar 2020].

36 Xu B, Gutierrez B, Mekaru S, et al. Epidemiological data from the COVID-19 outbreak, real-time case information. Sci Data 2020;7:1-6.

37 Zhu H. Transmission dynamics and control methodology of COVID-19: a modeling study. medRxiv 2020

38 Piccolomiini EL, Zama F. Monitoring Italian COVID-19 spread by an adaptive SEIRD model. medRxiv 2020

39 Tuite AR, Greer AL, Fisman DN. COVID-2019 transmission model. University of Toronto, 2020.

40 Holshue ML, DeBolt C, Lindquist S, et al. First case of 2019 novel coronavirus in the United States. N Engl J Med Overseas Ed 2020;382:929-36.

41 Kam K-Q, Yung CF, Cui L, et al. A well infant with coronavirus disease 2019 (COVID-19) with high viral load. Clin Infect Dis 2020;361. doi:10.1093/cid/ciaa201. [Epub ahead of print: 28 Feb 2020]

$42 \mathrm{Kim}$ JY, Ko JH, Kim Y, et al. Viral load kinetics of SARS-CoV-2 infection in first two patients in Korea. J Korean Med Sci 2020;35:e86

43 Kujawski SA, Wong KK, Collins JP, et al. First 12 patients with coronavirus disease 2019 (COVID-19) in the United States. medRxiv 2020

$44 \mathrm{Lim}$ J, Jeon S, Shin H-Y, et al. Case of the index patient who caused tertiary transmission of coronavirus disease 2019 in Korea: the application of lopinavir/ritonavir for the treatment of COVID-19 pneumonia monitored by quantitative RT-PCR. J Korean Med Sci 2020;35.

45 Marchand-Senécal X, Kozak R, Mubareka S, et al. Diagnosis and management of first case of COVID-19 in Canada: lessons applied from SARS. Clin Infect Dis 2020. doi:10.1093/cid/ciaa227. [Epub ahead of print: 09 Mar 2020].

46 Tan LV, Ngoc NM, That BTT, et al. Duration of viral detection in throat and rectum of a patient with COVID-19. medRiv 2020

47 Thevarajan I, Nguyen THO, Koutsakos M, et al. Breadth of concomitant immune responses prior to patient recovery: a case report of non-severe COVID-19. Nat Med 2020;26:453-5.

48 To KK-W, Tsang OT-Y, Chik-Yan Yip C, et al. Consistent detection of 2019 novel coronavirus in saliva. Clin Infect Dis 2020. doi:10.1093/ $\mathrm{cid} /$ ciaa149. [Epub ahead of print: 12 Feb 2020]

49 Woelfel R, Corman VM, Guggemos W, et al. Clinical presentation and virological assessment of hospitalized cases of coronavirus disease 2019 in a travel-associated transmission cluster. medRxiv 2020

50 Wölfel R, Corman VM, Guggemos W, et al. Virological assessment of hospitalized patients with COVID-2019. Nature 2020;581:465-9.

$51 \mathrm{Xu}$ T, Chen C, Zhu Z, et al. Clinical features and dynamics of viral load in imported and non-imported patients with COVID-19. Int J Infect Dis 2020;94:68-71.

52 Young BE, Ong SWX, Kalimuddin S, et al. Epidemiologic features and clinical course of patients infected with SARS-CoV-2 in Singapore. JAMA 2020;323:1488-94.

53 Zou L, Ruan F, Huang M, et al. SARS-CoV-2 viral load in upper respiratory specimens of infected patients. N Engl J Med 2020;382:1177-9.

54 Cao B, Wang $\mathrm{Y}$, Wen $\mathrm{D}$, et al. A trial of lopinavir-ritonavir in adults hospitalized with severe Covid-19. N Engl J Med 2020;382:1787-99.

55 Chen W, Lan Y, Yuan X, et al. Detectable 2019-nCoV viral RNA in blood is a strong indicator for the further clinical severity. Emerg Microbes Infect 2020;9:469-73.

56 Goh KJ, Choong MC, Cheong EH, et al. Rapid progression to acute respiratory distress syndrome: review of current understanding of critical illness from COVID-19 infection. Ann Acad Med Singapore 2020;49:1-9 
57 Hill KJ, Russell CD, Clifford S, et al. The index case of SARS-CoV-2 in Scotland. J Infect 2020;81:147-78.

58 Liu Y, Yan L-M, Wan L, et al. Viral dynamics in mild and severe cases of COVID-19. Lancet Infect Dis 2020;20:656-7.

59 To KK-W, Tsang OT-Y, Leung W-S, et al. Temporal profiles of viral load in posterior oropharyngeal saliva samples and serum antibody responses during infection by SARS-CoV-2: an observational cohort study. Lancet Infect Dis 2020;20:565-74.

60 Fang Z, Zhang Y, Hang C, et al. Comparisons of viral shedding time of SARS-CoV-2 of different samples in ICU and non-ICU patients. $J$ Infect 2020;81:147-78.

61 Kam K-Q, Yung CF, Cui L, et al. A well infant with coronavirus disease 2019 (COVID-19) with high viral load. Clin Infect Dis 2020:ciaa201.

62 Kimball A, Hatfield KM, Arons M, et al. Asymptomatic and presymptomatic SARS-CoV-2 infections in residents of a long-term care skilled nursing facility - King County, Washington, March 2020 MMWR Morb Mortal Wkly Rep 2020;69:377-81.

63 Ferretti L, Wymant C, Kendall M, et al. Quantifying SARS-CoV-2 transmission suggests epidemic control with digital contact tracing. Science 2020;368. doi:10.1126/science.abb6936. [Epub ahead of print: 08 May 2020].

64 Lavezzo E, Franchin E, Ciavarella C, et al. Suppression of COVID-19 outbreak in the municipality of VO, Italy. medRxiv 2020

65 Cereda D, Tirani M, Rovida F, et al. The early phase of the COVID-19 outbreak in Lombardy. arXiv 2020:arXiv:2003.09320v1.

66 Liao J, Fan S, Chen J, et al. Epidemiological and clinical characteristics of COVID-19 in adolescents and young adults. medRxiv 2020

67 Kupferschmidt K. Study claiming new coronavirus can be transmitted by people without symptoms was flawed. Science2020;3.

$68 \mathrm{Hu}$ F, Chen F, Wang Y, et al. Failed detection of the full-length genome of SARS-CoV-2 by ultra-deep sequencing from the recovered and discharged patients retested viral PCR positive. medRxiv 2020

69 Xing Y, Ni W, Wu Q, et al. Prolonged presence of SARS-CoV-2 in feces of pediatric patients during the convalescent phase. medRxiv 2020

70 Fu R, Gartlehner G, Grant M, et al. Conducting quantitative synthesis when comparing medical interventions: AHRQ and the effective health care program. J Clin Epidemiol 2011;64:1187-97.

71 Griffin JM, Collins AB, Hunt K, et al. A rapid review of available evidence on the serial interval and generation time of COVID-19. medRxiv. 2020

72 McAloon CG, Collins A, Hunt K, et al. The incubation period of COVID-19: a rapid systematic review and meta-analysis of observational research. medRxiv 2020

73 Lane EA, Barrett DJ, Casey M, et al. Country differences in hospitalisation length of stay and admission to intensive care units due to SARS-CoV-2 infection: a rapid review of available literature. medRxiv 2020
74 Zhou F, Yu T, Du R, et al. Clinical course and risk factors for mortality of adult inpatients with COVID-19 in Wuhan, China: a retrospective cohort study. Lancet 2020;395:1054-62.

75 Ferguson N, Laydon D, Nedjati Gilani G. Report 9: impact of nonpharmaceutical interventions (NPIs) to reduce COVID19 mortality and healthcare demand, 2020. Available: https://www.imperial.ac.uk/ media/imperial-college/medicine/sph/ide/gida-fellowships/ImperialCollege-COVID19-NPI-modelling-16-03-2020.pdf

76 Cai J, Xu J, Lin D, et al. A case series of children with 2019 novel coronavirus infection: clinical and epidemiological features. Clin Infect Dis 2020. doi:10.1093/cid/ciaa198. [Epub ahead of print: 28 Feb 2020].

77 Cai Q, Huang D, Ou P, et al. COVID-19 in a designated infectious diseases Hospital outside Hubei Province, China. Allergy 2020;75:1742-52.

78 Chen D, Xu W, Lei Z, et al. Recurrence of positive SARS-CoV-2 RNA in COVID-19: a case report. Int $J$ Infect Dis 2020;93:297-9.

79 Cheng S-C, Chang Y-C, Fan Chiang Y-L, et al. First case of coronavirus disease 2019 (COVID-19) pneumonia in Taiwan. $J$ Formos Med Assoc 2020;119:747-51.

80 Lee N-Y, Li C-W, Tsai H-P, et al. A case of COVID-19 and pneumonia returning from Macau in Taiwan: clinical course and anti-SARS-CoV-2 IgG dynamic. J Microbiol Immunol Infect 2020;53:S1684:30060-487.

81 Ling Y, Xu S-B, Lin Y-X, et al. Persistence and clearance of viral RNA in 2019 novel coronavirus disease rehabilitation patients. Chin Med J 2020;133:1039-43

82 Liu F, Xu A, Zhang Y, et al. Patients of COVID-19 may benefit from sustained lopinavir-combined regimen and the increase of eosinophil may predict the outcome of COVID-19 progression. Int $J$ Infect Dis 2020;95:183-91.

83 Qu Y-M, Kang E-M, Cong H-Y. Positive result of Sars-Cov-2 in sputum from a cured patient with COVID-19. Travel Med Infect Dis 2020;34:101619.

84 Yuan J, Kou S, Liang Y, et al. Clinical characteristics on 25 discharged patients with COVID-19 virus returning. medRxiv 2020

85 Chen J, Qi T, Liu L, et al. Clinical progression of patients with COVID-19 in Shanghai, China. J Infect 2020;80:e1-6.

86 Le HT, Nguyen LV, Tran DM, et al. The first infant case of COVID-19 acquired from a secondary transmission in Vietnam. Lancet Child Adolesc Health 2020;4:405-406.

87 Qiu H, Wu J, Hong L, et al. Clinical and epidemiological features of 36 children with coronavirus disease 2019 (COVID-19) in Zhejiang, China: an observational cohort study. Lancet Infect Dis 2020;20:689-96.

88 Wu Y, Guo C, Tang L, et al. Prolonged presence of SARS-CoV-2 viral RNA in faecal samples. Lancet Gastroenterol Hepatol 2020;5:434-5.

89 Lourenço J, Paton R, Ghafari M, et al. Fundamental principles of epidemic spread highlight the immediate need for large-scale serological surveys to assess the stage of the SARS-CoV-2 epidemic. medRxiv 2020 